\title{
LETTER FROM THE EDITORS
}

We present the current volume of the Journal of Clinical Speech and Language Studies with a mixture of pleasure tinged with sadness. This issue is dedicated to a remarkable individual who has touched the lives of so many involved in speech and language therapy, both here in Ireland and on the international arena - Dr Marie de Montfort Supple, who retires from the School of Clinical Speech and Language Studies in September, 1998. The papers presented in this volume give some indication both of the contribution she has made to the field, and of the respect which is paid to her by other leading international experts.

In her role as founder of the Dublin College of Speech Therapy, and Head of the School of Remedial Linguistics, subsequently the School of Clinical Speech and Language Studies, Dr de Montfort has brought us through an educational process which has resulted in the development of a vibrant and dedicated profession, well equipped to face the many challenges presented by changes in Healthcare and Education provision. Through her international work with the International Association of Logopedics and Phoniatrics (IALP) she has catapulted Ireland onto the International stage, paving the way for many others of us to forge links with colleagues all around the world.

We start the journal with a paper by 'Sister' herself, first published in 1994, celebrating the first quarter-century of the professional education of speech and language therapists in Ireland. Margaret Leahy, Head of the School of Clinical Speech and Language Studies then outlines some of the challenges facing all of us involved in supporting those with communication impairments, whether as direct service providers or as educators.

The subsequent papers in this issue are diverse, reflecting the very broad influence which has been the hallmark of Dr de Montfort's career. Margaret Leahy, Lilly Cheng, Jeri Logemann, Ewa Söderpalm and Kay Butler and were all invited to contribute to this issue honouring their colleague and friend. All responded promptly by setting pen to paper, and we thank them heartily for their generosity in sharing their expertise.

In conclusion, we would like to express our own very sincere and heartfelt thanks to Sr. de Montfort who has acted as teacher, colleague, mentor and friend. Ní bheidh a leithéad arís ann.

Martine Smith \& Irene Walsh 